\title{
Parmak ve el ölçüm değerleri ve sağ-sol değerler arasındaki farkın semen parametleri ile ilișkisi
}

\section{The relationship between finger and hand measurement values, and differences between right-left values with semen parameters}

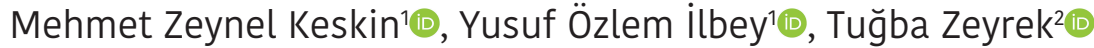

\section{öz}

AMAÇ: Parmak ve el ölçüm değerleri ile semen parametreleri arasındaki ilişkiyi incelemek.

GEREÇ ve YÖNTEM: Çalısmamıza hastanemiz erkek infertilitesi polikliniğine 2018 yılında başvuran 90 hasta prospektif olarak alındı. Ondalık $1 \mathrm{~mm}$ duyarlı cetvelle parmak ve el ölçüm değerleri (sağ $2 \mathrm{D}$, sağ 4D, sağ el genişliği, sağ el uzunluğu, sol 2D, sol 4D, sol el genişliği, sol el uzunluğu) saptandı. Bu değerlerle parmak oran değerleri (sağ 2D:4D oranı, sol 2D:4D oranı) hesaplandı. Parmak oran değerleriyle ise sağ-sol oran farklılıkları (sağ 2D:4D - sol 2D:4D değeri (Dr-l), sağ 2D:4D/sol 2D:4D oranı (Dr/l) ve 2D:4D asimetri indeksi [(sol 2D:4D - sağ 2D:4D)/(sol 2D:4D + sağ 2D:4D)] hesaplandı. Semen analizi parametreleri ile ölçüm değerleri arasındaki ilişki bi-variate korelasyon testi (spearman) ile incelendi. P değeri $<0,05$ istatistiksel olarak anlamlı kabul edildi.

BULGULAR: Semen parametreleri ile sağ ve sol el genişliği arasında negatif ilişki, sol el uzunluğu ve parmak 2D:4D oranları ile pozitif ilişki saptand.

SONUÇ: Prenatal dönemdeki testosteron maruziyetinin indirekt belirleyicisi olarak gösterilen sağ 2D:4D ve sol 2D:4D oranı ile semen parametreleri arasında literatür verileri ışığında negatif korelasyon çıkması beklenirken, bizim çalıșmamızda pozitif korelasyon çıkmıștır. Ve özellikle ilginç olan sağ (dört parametre) ve sol (beş parametre) el genişliğinin ise en fazla semen parametreleri ile negatif korelasyon içeren ölçüm değeri olmasıdır. El genişliği prenatal dönemdeki testosteron için yeni bir belirleyici olabilir mi? Bu soruyu yanıtlamak ve kesin patofizyolojiyi aydınlatmak için daha çok sayıda vaka içeren, prospektif ve randomize çalışmalara ihtiyaç olduğu açıktır.

Anahtar Kelimeler: El genişliği, parmak asimetri indeksi, semen

\section{GíRiș}

2D:4D oranının prenatal dönemdeki testosteron düzeyiyle yakından ilişkili olduğu ve bu oranın düşük olduğu bireylerde yüksek olanlara göre prenatal dönemde daha yüksek

${ }^{1}$ Tepecik Eğitim ve Araştırma Hastanesi, Üroloji Kliniği, İzmir, Türkiye

${ }^{2}$ Tepecik Eğitim ve Araştırma Hastanesi, Embriyoloji Kliniği, İzmir, Türkiye

Yazıșma Adresi/ Correspondence:

Uzm. Dr. Mehmet Zeynel Keskin

512.sok No: 30 D: 1 Aktas Apt. Sirinyer/izmir 35150 Izmir, Türkiye

Tel. +905301184583

E-mail: zeynel_akd@hotmail.com

Gelis/ Received: $\quad 14.08 .2018$

Kabul/ Accepted: $\quad 08.10 .2018$

\section{ABSTRACT}

OBJECTIVE: To investigate the relationship between hand and finger measurement values and semen parameters.

MATERIAL and METHODS: Ninety patients who applied to the male infertility polyclinic of our hospital in 2018 were included in the study prospectively. Finger and hand measurement values (right $2 \mathrm{D}$, right $4 \mathrm{D}$, right hand width, right hand length, left $2 \mathrm{D}$, left $4 \mathrm{D}$, left hand width, left hand length) were determined using a ruler with $1 \mathrm{~mm}$ accuracy. Other parameters were calculated by using these digit ratio values. The relationship between semen parameters and measurement values were analysed by bi-variate correlation test (Spearman). P value $<0.05$ was considered statistically significant.

RESULTS: Left and right hand width has a negative correlation with semen parameters and left hand length and finger 2D:4D ratios has positive correlations.

CONCLUSION: Contrary to the literature data, a positive correlation was found in our study between the semen parameters and the right $2 \mathrm{D}: 4 \mathrm{D}$ and left 2D:4D ratios, which are shown as indirect determinants of testosterone exposure in the prenatal period. Interestingly, the right (4 parameters) and left (5 parameters) hand widths were the measurement values indicating the most negative correlation with the semen parameters. Can hand width be a new determinant for testosterone exposure in the prenatal period? It is clear that prospective and randomized studies with more cases are needed to answer this question and to clarify the exact pathophysiology.

Keywords: Hand width, finger asymmetry index, semen

testosteron maruziyeti olduğu raporlanmıştır. ${ }^{[1]}$ Erkeklerde bu oran daha düşük bulunmuştur ve bu oranın büyük olduğu kadınlarda reprodüktif başarı daha yüksek saptanmıştır. ${ }^{[2,3]}$ Genetik açıdan bakıldığında, homeobox geninin bir bölümü olan Hoxa ve Hoxd geni omurgalılarda hem ekstremitelerin hem de genital yapının gelişmesinde rol oynamaktadır. ${ }^{[4]}$ Hoxa geninde meydana gelen bir mutasyon insanlarda parmaklar ve genital bölgede anatomik defektlerle ortaya çıkan sendroma neden olmaktadır. ${ }^{[5]}$

Literatürde penis uzunluğu, prematür ejakülasyon, erkek reprodüktif hormon düzeyleri ve benzeri konuların bu oranla ilişkisi birçok çalışmaya konu olmuştur. ${ }^{[6-8]}$ 
Çalışmamızda, literatürde bu kadar ilgiyle ele alınan parmak ölçüm değerlerinin semen parametreleri ile ilişkisini inceledik.

\section{GEREÇ VE YÖNTEM}

Ocak-Şubat 2018 tarihleri arasında hastanemiz üroloji kliniğine infertilite şikâyeti ile başvuran 90 primer infertil hasta hastanemiz etik kurulundan onay alındıktan sonra prospektif olarak çalışma için değerlendirildi. Hastaların anamnez ve fizik muayenesi yapıldıktan sonra varikosel saptanan ya da varikoselektomi öyküsü olan, genital travma, geçirilmiş orşit öyküsü, geçirilmiş el ve parmak cerrahisi öyküsü, hipogonadotropik hipogonadizm, klinefelter sendromlu hastalar ve testosteron düzeyini etkileyebilecek patolojisi olan ya da semen parametrelerini etkileyebilecek ilaç kullanımı olan hastalar çalışma dışı bırakıldı. Hastaların sağ ve sol işaret (2D) ve yüzük (4D) parmak uzunlukları ve sağ ve sol el genişlik ile uzunlukları ölçüldü. Ölçüm elin dorsal yüzünden cetvel yardımıyla direkt ölçüm yöntemiyle her ölçüm en az iki kere yapıldıktan sonra ortalama değerleri hesaplanarak yapıldı. Ölçüm için $1 \mathrm{~mm}$ duyarlı ondalık göstergeli sert plastik cetvel kullanıld. Parmak uzunlukları için metakarpofalangeal bileşke ile parmak ucu, el genişliği için 2. metakarpofalengeal bileşkeler ile 5. metakarpofalangeal bileşkenin oluşturduğu yatay çizginin ciltten cilde uzunluğu, el uzunluğu için el bilek ekleminin 3. parmak ekseni ile kesiştiği noktanın üçüncü parmağın en ucuna olan uzaklığı referans alınmıştır. Sonuç olarak; sağ 2D (sağ işaret parmağı uzunluğu), sağ $4 \mathrm{D}$ (sağ yüzük parmağı uzunluğu), sağ el genişliği, sağ el uzunluğu, sol 2D (sol işaret parmağı uzunluğu), sol 4D (sol yüzük parmağı uzunluğu), sol el genişliği, sol el uzunluğu, sağ 2D:4D (sağ işaret parmağı uzunluğunun sağ yüzük parmağı uzunluğuna oranı), sol2D:4D (sol işaret parmağı uzunluğunun sol yüzük parmağı uzunluğuna oranı), Dr-1 (sağ işaret parmağı uzunluğunun sağ yüzük parmağı uzunluğuna oranı ile sol işaret parmağı uzunluğunun sol yüzük parmağı uzunluğuna oranı arasındaki fark), Dr/l (sağ işaret parmağı uzunluğunun sağ yüzük parmağı uzunluğuna oranının, sol işaret parmağı uzunluğunun sol yüzük parmağı uzunluğuna oranına bölünmesi ile elde edilen değer), asimetri indeksi [ (sol 2D:4D - sağ 2D:4D)/(sol 2D:4D + sağ 2D:4D)] değerleri ardışık olarak elde edildi.

Semen analizi 3-5 günlük cinsel perhiz sonrası alındı. Semen analizinde anormallik saptanan hastalardan en az iki semen analizi çalışıldı ve ortalama değerler kullanıldı. Semen analizi WHO 2010 kriterlerine (semen volüm $\geq 1,5$ $\mathrm{ml}$; sperm konsantrasyonu $\geq 15 \times 10^{6} / \mathrm{ml}$; toplam motilite $\geq \% 40$, ileri motilite $\geq \% 32$ ve morfoloji $\geq \% 4$ ) göre yapıldi. ${ }^{\left[{ }^{[0]}\right.}$ Örneğin verilmesinden itibaren semen 5-30 dakika içerisinde likefiye olduktan sonra değerlendirmeye alındı. Renk, koku ve viskozite gibi özellikleri de belirlenerek kaydedildi. Semen analizinde mikroskobik değerlendirme için faz-kontrast ışık mikroskobu kullanıldı ve değerlendirmeler 10x20 büyütmede yapıldı. Sperm konsantrasyonu için Makler sayım kamarası kullanılarak 100 karelik alan içinde 10 karedeki sperm sayısı ile milyon/ml'deki sperm sayısı (konsantrasyon) bulundu. Sağlıklı bir sonuç alabilmek için birden fazla (en az dört) 10 kare sayılarak ortalamaları alındı. Hareketlilik; doğrusal ilerleyici hareket, yerinde hareket, hareketsiz olmak üzere üç grupta değerlendirildi. Morfolojik inceleme için daha önceden \%70'lik etanol ile yıkanmış lamlara sperm konsantrasyonuna göre damlatılan semen örneği 45 derecelik açı ile yayılarak kurutuldu. Daha sonra Diff-Quick kiti ile boyandıktan sonra 100X objektifte immersiyon yağı altında en az 200 sperm değerlendirilerek \%normal morfolojili sperm oranı belirlendi.

Semen parametreleri ile parmak ölçüm değerleri arasındaki ilişki verilerin normal dağılıma uygun olmaması nedeniyle bi-variate korelasyon testi (Spearman) ile incelendi. $\mathrm{p}<0,05$ değeri istatistiksel olarak anlamlı kabul edildi.

\section{BULGULAR}

Çalışmaya dahil edilen 90 hastanın yaş aralığı 19-49 yıl ve ortalama yaş değeri $32,94 \pm 5,88$ yıl idi.

Hastaların parmak ölçüm değeri aralıkları, ortalama ve standart sapma değerleri; sağ 2D için sırasıyla 85-112 $\mathrm{mm}$ ve $98,03 \pm 5,6 \mathrm{~mm}$, sağ $4 \mathrm{D}$ için $91-115 \mathrm{~mm}$ ve $102,76 \pm 6,01 \mathrm{~mm}$, sağ el genişliği için $85-123 \mathrm{~mm}$ ve $96,04 \pm 6,23$, sağ el uzunluğu için $178-230 \mathrm{~mm}$ ve $204,04 \pm 11,13 \mathrm{~mm}$, sol 2D için sırasıyla $84-110 \mathrm{~mm}$ ve $96,62 \pm 5,37 \mathrm{~mm}$, sol 4D için $89-117 \mathrm{~mm}$ ve $101,92 \pm 6,11$ $\mathrm{mm}$, sol el genişliği için $85-124 \mathrm{~mm}$ ve $95,78 \pm 6,69$, sol el uzunluğu için $175-228 \mathrm{~mm}$ ve $203,77 \pm 10,71 \mathrm{~mm}$; sağ $2 \mathrm{D}: 4 \mathrm{D}$ için $0,9-1,01$ ve $0,95 \pm 0,024$, sol $2 \mathrm{D}: 4 \mathrm{D}$ için $0,89-1,05$ ve $0,94 \pm 0,02$, Dr-1 için $[(-0,09)-(+0,07) \mathrm{mm}]$ ve $0,05 \pm 0,026, \mathrm{Dr} / 1$ için $0,91-1,07$ ve $1,00 \pm 0,027$, asimetri indeksi için $[(-0,04)-(+0,05)]$ ve $[(-0,0030) \pm 0,013]$ olarak saptandı. Hastaların semen parametrelerinin değer aralıkları, ortalama ve standart sapma değerleri; semen volümü için $0,4-8 \mathrm{~mL}$ ve $2,76 \pm 1,54 \mathrm{~mL}$, konsantrasyon için $0-168 \times 106 / \mathrm{mL}$ ve $22,42 \pm 33,90 \times 10^{6} / \mathrm{mL}$, total motilite için $\% 0-80$ ve $\% 36,62 \pm 28,92$, progresif motilite için $\% 0-70$ ve $\% 25,41 \pm 22,62$, Total sperm sayısı için (TSS) $0-455 \times 10^{6}$ adet ve $60 \pm 102,62 \times 10^{6}$ adet, Total motil sperm sayısı için (TMSS) $0-280 \times 10^{6}$ adet ve 33,61 $\pm 59,68 \times 106$ adet, Total progresif motil sperm sayısı için (TPMSS) $0-227 \times 10^{6}$ adet ve $24,26 \pm 45,91 \times 10^{6}$ adet, hizlı ileri sperm yüzdesi (a) için \%0-60 ve \%7,52 111,48 , yavaş ileri sperm 
yüzdesi (b) için \%0-55 ve \%17,88 $\% 15,80$, yerinde hare-

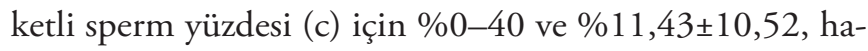

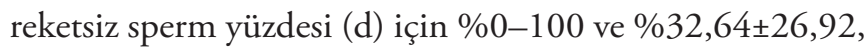
Kruger'e göre normal morfolojili sperm yüzdesi için $\% 0-8$ ve $\% 1,55 \pm 2,08$, baş anomalili sperm yüzdesi için \%0-91 ve $\% 37,47 \pm 39,98$, boyun anomalili sperm yüzdesi için $\% 0-18$ ve $\% 4,89 \pm 5,55$, kuyruk anomalili sperm yüzdesi

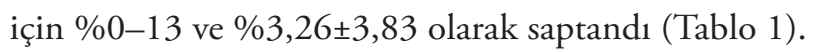

Hastaların parmak ölçüm değerleri ile semen parametreleri arasındaki ilişki Spearman korelasyon analizi ile yapıldı Sağ 4D ile d arasında negatif ( $p=0,027)$, sağ el genişliği ile sırasıyla; konsantrasyon, TSS, c, d arasında negatif (sırasıyla; $\mathrm{p}=0,024, \mathrm{p}=0,034, \mathrm{p}=0,047, \mathrm{p}=0,007$ ), sağ el uzunluğu ile semen volümü arasında pozitif $(\mathrm{p}=0,224)$, sol $4 \mathrm{D}$ ile $\mathrm{d}$ arasında negatif ( $p=0,03)$, sol el genişliği ile sırasıyla; konsantrasyon, TSS, TMSS, TPMSS, a, c, d, boyun anomalisi,

Tablo 1. Hastaların ortalama verileri

\begin{tabular}{|c|c|c|c|c|}
\hline & Min. & Maks. & Ort. & Std. Sap. \\
\hline Yaş (yıl) & 20 & 49 & 32,94 & 5,886 \\
\hline Volüm (mL) & 0,40 & 8,00 & 2,7652 & 1,54236 \\
\hline Konsantrasyon (x 106/mL) & 0,00 & 168,00 & 22,4258 & 33,90246 \\
\hline TM (\%) & 0,00 & 80,00 & 36,6292 & 28,92757 \\
\hline PM (\%) & 0,00 & 70,00 & 25,4157 & 22,62933 \\
\hline TSS (x $10^{6}$ adet) & 0,00 & 455,00 & 60,0083 & 102,62760 \\
\hline TMSS (x $10^{6}$ adet) & 0,00 & 280,00 & 33,6192 & 59,68590 \\
\hline TPMSS (x $10^{6}$ adet) & 0,00 & 227,50 & 24,2629 & 45,91582 \\
\hline a (\%) & 0,00 & 60,00 & 7,5281 & 11,48427 \\
\hline b (\%) & 0,00 & 55,00 & 17,8876 & 15,80308 \\
\hline c (\%) & 0,00 & 40,00 & 11,4382 & 10,52049 \\
\hline$d(\%)$ & 0,00 & 100,00 & 32,6404 & 26,92677 \\
\hline Normal morfoloji (\%) & 0,00 & 8,00 & 1,5506 & 2,08355 \\
\hline Baş anomalisi (\%) & 0,00 & 91,00 & 37,4719 & 39,98269 \\
\hline Boyun anomalisi (\%) & 0,00 & 18,00 & 4,8989 & 5,55355 \\
\hline Kuyruk anomalisi (\%) & 0,00 & 13,00 & 3,2697 & 3,83987 \\
\hline Sağ 2D (mm) & 85,00 & 112,00 & 98,0337 & 5,60124 \\
\hline Sağ 4D (mm) & 91,00 & 115,00 & 102,7640 & 6,01517 \\
\hline Sağ el Genişliği (mm) & 85,00 & 123,00 & 96,0449 & 6,23755 \\
\hline Sağ el uzunluğu (mm) & 178,00 & 230,00 & 204,0449 & 11,13135 \\
\hline Sol 2D (mm) & 84,00 & 110,00 & 96,6292 & 5,37118 \\
\hline Sol 4D (mm) & 89,00 & 117,00 & 101,9213 & 6,11486 \\
\hline Sol genişlik (mm) & 85,00 & 124,00 & 95,7865 & 6,69714 \\
\hline Sol uzunluk (mm) & 175,00 & 228,00 & 203,7753 & 10,71824 \\
\hline Sağ 2D: 4D & 0,90 & 1,01 & 0,9544 & 0,02462 \\
\hline Sol 2D: 4D & 0,89 & 1,05 & 0,9487 & 0,02669 \\
\hline Dr-I & $-0,09$ & 0,07 & 0,0057 & 0,02631 \\
\hline $\mathrm{Dr} / \mathrm{I}$ & 0,91 & 1,07 & 1,0064 & 0,02759 \\
\hline Asimetri İndeksi & $-0,04$ & 0,05 & $-0,0030$ & 0,01374 \\
\hline
\end{tabular}

TM, total motilite; PM, progresif motilite; TSS, total sperm sayısı; TMSS, total motil sperm sayısı; TPMSS, total progresif motil sperm sayısı; a, hızlı ileri hareketli sperm yüzdesi; b, yavaş ileri hareketli sperm yüzdesi; c, yerinde hareketli sperm yüzdesi; d, hareketsiz sperm yüzdesi; Sağ 2D, sağ işaret parmağı uzunluğu; Sağ 4D, sağ yüzük parmağı uzunluğu; Sol 2D, sol işaret parmağı uzunluğu; Sol 4D, sol yüzük parmağı uzunluğu; Sağ 2D:4D, sağ işaret parmağı uzunluğunun sağ yüzük parmağı uzunluğuna oranı; Sol 2D:4D, sol işaret parmağı uzunluğunun sol yüzük parmağı uzunluğuna oranı; Dr-I, sağ işaret parmağı uzunluğunun sağ yüzük parmağı uzunluğuna oranı ile sol işaret parmağı uzunluğunun sol yüzük parmağı uzunluğuna oranı arasındaki fark; Dr/l, sağ işaret parmağı uzunluğunun sağ yüzük parmağı uzunluğuna oranının; sol işaret parmağı uzunluğunun sol yüzük parmağı uzunluğuna oranına bölünmesi ile elde edilen değer, Min.; minimum, Maks.; maksimum; Ort., ortalama; Std. Sap., standart sapma. 
kuyruk anomalisi arasında negatif (sırasıyla; $\mathrm{p}=0,008$, $\mathrm{p}=0,016, \mathrm{p}=0,027, \mathrm{p}=0,025, \mathrm{p}=0,049, \mathrm{p}=0,039, \mathrm{p}=0,038$, $\mathrm{p}=0,016, \mathrm{p}=0,037)$, sağ 2D:4D ile sırasıyla; konsantrasyon, PM, TSS, TMSS, TPMSS, baş anomalisi arasında pozitif (sirasiyla; $\mathrm{p}=0,028, \mathrm{p}=0,029, \mathrm{p}=0,029, \mathrm{p}=0,032, \mathrm{p}=0,025$, $\mathrm{p}=0,043)$, sol 2D:4D ile $\mathrm{c}$ arasında pozitif $(\mathrm{p}=0,004)$ korelasyon saptandi. Sağ 2D, sol 2D, Dr-1, Dr/l ve asimetri indeksi ile hiç bir semen parametresi arasında anlamlı korelasyon saptanmadı (Tablo 2).

\section{TARTIȘMA}

Literatüre bakıldığında 2D:4D oranı prenatal testosteron için bir belirteç olarak gösterilmiştir. Oran düştükçe prenatal dönemde maruz kalınan $\mathrm{T}$ düzeyinin arttığı, $\mathrm{E}$

Tablo 2. Parmak ve el ölçüm değerleri, sağ-sol değerler arasındaki farkın semen parametreleri ile ilişkisinin Spearman korelasyon analizi sonuçları

\begin{tabular}{|c|c|c|c|c|c|c|c|c|c|c|c|c|c|c|}
\hline & & Sağ $2 D$ & Sağ 4D & $\begin{array}{l}\text { Sağ El } \\
\text { Gen. }\end{array}$ & $\begin{array}{l}\text { Sağ El } \\
\text { Uzun. }\end{array}$ & Sol 2D & Sol 4D & $\begin{array}{l}\text { Sol El } \\
\text { Gen. }\end{array}$ & $\begin{array}{l}\text { Sol El } \\
\text { Uzun. }\end{array}$ & $\begin{array}{c}S a g ̆ \\
2 D: 4 D\end{array}$ & $\begin{array}{c}\text { Sol } \\
2 D: 4 D\end{array}$ & Dr-I & $\mathrm{Dr} / \mathrm{I}$ & $\begin{array}{c}\text { Asim. } \\
\text { in. }\end{array}$ \\
\hline \multirow{2}{*}{ Vol. } & K. K & 0,108 & 0,126 & 0,088 & $0,224^{*}$ & 0,166 & 0,117 & 0,108 & 0,279 & $-0,09$ & $-0,004$ & $-0,109$ & $-0,104$ & 0,103 \\
\hline & P değ. & 0,312 & 0,241 & 0,412 & 0,035 & 0,119 & 0,277 & 0,315 & 0,008 & 0,4 & 0,971 & 0,307 & 0,334 & 0,335 \\
\hline \multirow{2}{*}{ Kons. } & K. K & $-0,089$ & $-0,18$ & $-0,239^{*}$ & $-0,069$ & $-0,143$ & $-0,188$ & $-0,278^{* *}$ & $-0,122$ & $0,234^{*}$ & 0,186 & 0,05 & 0,048 & $-0,048$ \\
\hline & $P$ değ. & 0,408 & 0,092 & 0,024 & 0,518 & 0,18 & 0,078 & 0,008 & 0,256 & 0,028 & 0,08 & 0,641 & 0,652 & 0,652 \\
\hline \multirow{2}{*}{ TM } & K. K & 0,01 & $-0,044$ & $-0,086$ & $-0,034$ & 0,002 & $-0,041$ & $-0,187$ & $-0,041$ & 0,183 & 0,112 & 0,056 & 0,053 & $-0,053$ \\
\hline & $P$ değ. & 0,929 & 0,682 & 0,421 & 0,752 & 0,983 & 0,702 & 0,08 & 0,706 & 0,086 & 0,298 & 0,604 & 0,621 & 0,62 \\
\hline \multirow{2}{*}{ PM } & K. K & 0,009 & $-0,078$ & $-0,089$ & $-0,031$ & $-0,038$ & $-0,06$ & $-0,193$ & $-0,047$ & $0,231 *$ & 0,08 & 0,125 & 0,121 & $-0,121$ \\
\hline & P değ. & 0,932 & 0,47 & 0,406 & 0,776 & 0,727 & 0,577 & 0,07 & 0,662 & 0,029 & 0,454 & 0,244 & 0,258 & 0,257 \\
\hline \multirow{2}{*}{ TSS } & K. K & $-0,065$ & $-0,159$ &,$- 225 *$ & $-0,022$ & $-0,116$ & $-0,166$ & $-0,254^{*}$ & $-0,078$ & $0,231 *$ & 0,194 & 0,04 & 0,039 & $-0,039$ \\
\hline & P değ. & 0,547 & 0,136 & 0,034 & 0,839 & 0,281 & 0,12 & 0,016 & 0,467 & 0,029 & 0,069 & 0,713 & 0,715 & 0,715 \\
\hline \multirow{2}{*}{ TMSS } & K. K & $-0,072$ & $-0,161$ & $-0,18$ & $-0,047$ & $-0,115$ & $-0,17$ & $-0,234 *$ & $-0,09$ & $0,227 *$ & 0,2 & 0,027 & 0,026 & $-0,026$ \\
\hline & $P$ değ. & 0,5 & 0,133 & 0,092 & 0,665 & 0,285 & 0,112 & 0,027 & 0,402 & 0,032 & 0,06 & 0,802 & 0,807 & 0,807 \\
\hline \multirow{2}{*}{ TPMSS } & K. K & $-0,073$ & $-0,167$ & $-0,176$ & $-0,056$ & $-0,122$ & $-0,166$ & $-0,238^{*}$ & $-0,099$ & $0,238 *$ & 0,181 & 0,052 & 0,051 & $-0,051$ \\
\hline & P değ. & 0,497 & 0,119 & 0,1 & 0,6 & 0,255 & 0,119 & 0,025 & 0,355 & 0,025 & 0,09 & 0,629 & 0,637 & 0,637 \\
\hline \multirow{2}{*}{ a } & K. K & 0,046 & $-0,027$ & $-0,073$ & $-0,036$ & $-0,014$ & $-0,021$ & $-0,209 *$ & $-0,03$ & 0,186 & 0,055 & 0,123 & 0,121 & $-0,121$ \\
\hline & $P$ değ. & 0,67 & 0,8 & 0,496 & 0,741 & 0,895 & 0,843 & 0,049 & 0,777 & 0,081 & 0,606 & 0,251 & 0,261 & 0,26 \\
\hline \multirow{2}{*}{ b } & K. K & $-0,03$ & $-0,101$ & $-0,117$ & $-0,049$ & $-0,044$ & $-0,099$ & $-0,201$ & $-0,086$ & 0,191 & 0,114 & 0,042 & 0,038 & $-0,039$ \\
\hline & $P$ değ. & 0,781 & 0,345 & 274 & 0,648 & 0,682 & 0,354 & 0,059 & 0,421 & 0,073 & 0,289 & 0,695 & 0,721 & 0,719 \\
\hline \multirow{2}{*}{ c } & K. K & $-0,134$ & $-0,143$ & $-0,211^{*}$ & $-0,096$ & $-0,079$ & $-0,192$ & $-0,219 *$ & $-0,117$ & 0,114 & $0,304 * *$ & $-0,202$ & $-0,199$ & 0,199 \\
\hline & $P$ değ. & 0,21 & 0,18 & 0,047 & 0,37 & 0,461 & 0,072 & 0,039 & 0,273 & 0,288 & 0,004 & 0,058 & 0,061 & 0,061 \\
\hline \multirow{2}{*}{ d } & K. K & $-0,17$ & $-0,234^{*}$ & $-0,282 * *$ & $-0,044$ & $-0,203$ & $-0,230 *$ & $-0,221 *$ & $-0,14$ & 0,189 & 0,182 & $-0,013$ & $-0,011$ & 0,011 \\
\hline & P değ. & 0,111 & 0,027 & 0,007 & 0,682 & 0,056 & 0,03 & 0,038 & 0,191 & 0,077 & 0,087 & 0,904 & 0,919 & 0,918 \\
\hline \multirow{2}{*}{ Norm. } & K. K & $-0,032$ & $-0,097$ & $-0,186$ & $-0,041$ & $-0,077$ & $-0,108$ & $-0,2$ & $-0,071$ & 0,152 & 0,138 & 0,034 & 0,031 & $-0,031$ \\
\hline & P değ. & 0,769 & 0,365 & 0,081 & 0,702 & 0,475 & 0,313 & 0,06 & 0,507 & 0,154 & 0,197 & 0,753 & 0,773 & 0,774 \\
\hline \multirow{2}{*}{ Baş. } & K. K & $-0,02$ & $-0,106$ & $-0,208$ & $-0,04$ & $-0,092$ & $-0,128$ & $-0,2$ & $-0,103$ & $0,215^{*}$ & 0,097 & 0,12 & 0,118 & $-0,118$ \\
\hline & $P$ değ. & 0,853 & 0,323 & 0,051 & 0,709 & 0,391 & 0,233 & 0,06 & 0,338 & 0,043 & 0,367 & 0,264 & 0,271 & 0,271 \\
\hline \multirow{2}{*}{ Boyun } & K. K & $-0,049$ & $-0,112$ & $-0,229 *$ & $-0,048$ & $-0,102$ & $-0,12$ & $-0,254 *$ & $-0,096$ & 0,15 & 0,081 & 0,073 & 0,071 & $-0,071$ \\
\hline & $P$ değ. & 0,647 & 0,295 & 0,031 & 0,652 & 0,34 & 0,263 & 0,016 & 0,369 & 0,161 & 0,451 & 0,496 & 0,51 & 0,509 \\
\hline \multirow{2}{*}{ Kyrk } & K. K & 0,027 & $-0,031$ & $-0,187$ & 0,037 & $-0,024$ & $-0,054$ & $-0,222 *$ & $-0,015$ & 0,131 & 0,095 & 0,031 & 0,029 & $-0,029$ \\
\hline & P değ. & 0,8 & 0,771 & 0,079 & 0,728 & 0,82 & 0,618 & 0,037 & 0,89 & 0,222 & 0,376 & 0,771 & 0,787 & 0,787 \\
\hline \multicolumn{15}{|c|}{ 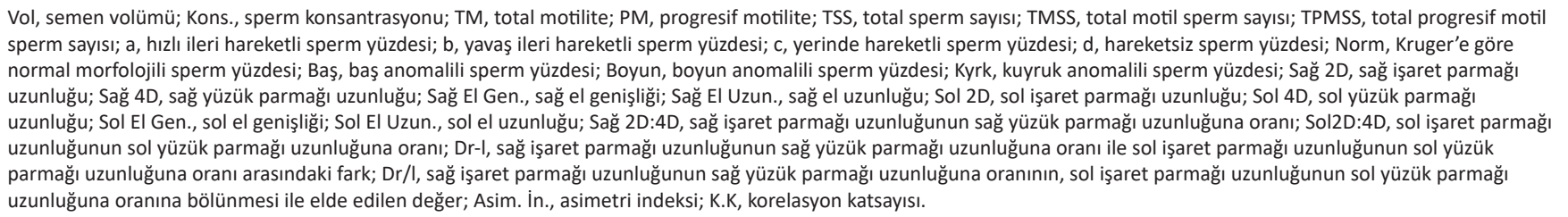 } \\
\hline
\end{tabular}


düzeyinin ise azaldığı raporlanmıştır. ${ }^{[1]} 2 \mathrm{D}: 4 \mathrm{D}$ oranının erişkin penis uzunluğu ile ilişkisi incelenen bir çalışmada, adult penis uzunluğunun prenatal dönemdeki testosteron düzeyinden etkilendiği sonucuna varılmıştır. ${ }^{[6]}$ Auger ve ark., çalışmalarında 2D:4D parmak oranının fertil hastalarda testis volümüyle negatif korele olduğunu bildirmişlerdir. ${ }^{[10]}$ Bir başka çalışmada, 2D:4D oranı ile testis volümü arasında ters orantı saptanmıştır. ${ }^{[11]}$

Prematür ejakülasyonla ilişkisine bakılan bir çalışmada ise 2D:4D oranı ile prematür ejakülasyon sıklığı arasında ters orantı saptanmış ve yazar bu ilişki yüksek testosteron maruziyetinin erişkin dönemde prematür ejakülasyon için risk oluşturduğu şeklinde açıklamıştır. ${ }^{[7]}$

Yapılan bir meta-analizde 2D:4D oranının bazı çalışmalarda erişkin serum seks hormon düzeyleri ile ilişkili saptanmış olsa da, 2D:4D oranı ve Dr-l değerinin erişkin serum seks hormon düzeyleriyle korele olmadığını, ilgili parametrelerin sadece prenatal androjenizasyonla ve onunla ilişkili olan insan davranışları ve kognisyonla alakalı olduğu bildirilmiştir. ${ }^{[12]}$ Manning ve ark.'nın çalışmasında, özellikle sağ 2D:4D oranının erişkin serum testosteron düzeyiyle kuvvetli korele olduğu saptanmıştır. ${ }^{[1]}$ Bazı meta-analizlerde sağ 2D:4D oranının kadınlara göre erkeklerde daha düşük olduğu ve cinsiyetler arasındaki farklılığı sağ 2D:4D oranının sola göre daha iyi yansıttığı saptanmıştır. ${ }^{[2,13]}$

Semen parametreleri ile olan ilişki mantıksal açıdan incelendiğinde ise düşük 2D:4D oranı olan erkeklerde semen kalitesinin daha iyi olması beklenir fakat literatürde aksi yönde sonuçlar veren çalışmalar mevcuttur. Bang ve ark. çalışmasında 2D:4D oranının total sperm sayısı ile pozitif korele olduğu saptanmıştır. ${ }^{[14]}$ Bir başka çalışmada ise $\mathrm{Lu}$ ve ark. Infertil erkeklerde 2D:4D oranı ile sperm motilitesi arasında ters ilişki saptamış fakat fertil erkeklerde ise bu ilişki görülememiştir. ${ }^{[15]}$ Bir başka çalışmada ise benzer ters ilişki fertil erkeklerdeki sperm sayısı ile saptanmış, infertil erkeklerde ise saptanmamıştır. ${ }^{[11]}$ Semen parametreleri ile sadece sağ 2D:4D oranının negatif korele olduğunu saptayan çalışmalar olduğu gibi, sağ ve/veya sol 2D:4D oranı ile semen parametrelerinin ilişkisiz olduğunu belirten çalışmalar da mevcuttur. ${ }^{[1,16,17]}$ Akinsal ve ark., oligospermik gruplar ile kontrol grubu arasında 2D:4D oranında farklilık saptamazken, vasal agenezi ve hipogonadotropik hipogonadizm olan gruplarda kontrol grubuna göre 2D:4D oranının istatistiksel olarak anlamlı düzeyde yüksek olduğunu saptamışlardır. ${ }^{[18]}$

Bizim çalışmamızda ise mantıksal açıdan beklenenin aksine 2D:4D oranı ile semen parametreleri arasında pozitif korelasyon saptanmış (sağ 2D:4D ile konsantrasyon, PM, TSS, TMSS, TPMSS, baş anomalisi; sol 2D:4D ile yerinde hareketli (c) sperm yüzdesi) ve bu korelasyonun sağ taraf için daha yüksek olduğu görülmüşsür.

Fakat çalışmamızda sağ el genişliği ile beş semen parametresi (konsantrasyon, TSS, yerinde hareketli (c) ve hareketsiz (d) yüzdesi, boyun anomalisi) arasında negatif korelasyon saptanırken, sol el genişliği ise sağ el genişliği ile negatif korele olan beş parametreye ilaveten dört semen parametresinde negatif yönde daha yüksek bir korelasyon bulunmuştur. (toplam dokuz parametre) (konsantrasyon, TSS, TMSS, TPMSS, ileri hareketli (a), yerinde hareketli (c) ve hareketsiz (d) yüzdesi, boyun ve kuyruk anomalisi). Dikkati çeken bir başka nokta ise sol el genişliğindeki korelasyon katsayılarının daha yüksek negatif olmasıdır.

Sağ ve sol el uzunluğunun ise sadece semen volümü ile pozitif korele olduğu görülmüş ve yine solda korelasyon katsayısının daha yüksek olduğu saptanmıştır.

Çalışmamızdan elde ettiğimiz bulgulara göre, literatürün aksine prenatal yüksek T maruziyetinin (indirekt göstergesi düşük 2D:4D) adult dönemde semen parametrelerini olumsuz etkilediği yönündedir. Başka açıdan bakacak olursak, prenatal yüksek $\mathrm{T}$ düzeyi adult dönemde semen parametrelerine olumlu yönde yansımaktadır fakat indirekt belirteci azalmış 2D:4D oranı değil sağ ya da sol el genişliği olabilir.

Bizim çalışmamızı ilginç kılan, literatürde henüz el uzunluğu ve prenatal $\mathrm{T}$ maruziyeti ilişkisini araştıran çalışmanın olmaması ve bu yönüyle yapılan ilk çalışma olmasıdır. Fakat, çıkardığımız bu sonucu doğrulamak ve patofizyolojiyi daha kesin bir şekilde aydınlatmak için daha fazla sayıda prospektif, daha geniş hasta sayılı ve randomize çalışmalara ihtiyaç olduğu açıktır.

Çalışmanın sadece primer infertil hastalar ile yapılmış olması ve kontrol hasta grubunun olmaması, obesite ile ilgili verilerin olmaması, sigara ve alkol kullanımının sorgulanmamış olması ve hastalarımızın genel üroloji polikliniği hastaları değil de infertilite hastaları olması nedeniyle subgrup analizlerinin yapılmamış olması çalışmamızın kısıtlı yanlarını oluşturmaktadır.

\section{Hakem Değerlendirmesi}

Dış bağımsız

Çıkar Çatışması

Yazarlar çıkar ilişkisi olmadığını beyan etmişlerdir.

Finansal Destek

Herhangi bir mali destek alınmamıştır.

\section{Peer-review}

Externally peer-reviewed.

Conflict of Interest

No conflict of interest was declared by the authors.

Financial Disclosure

No financial disclosure was received. 


\section{KAYNAKLAR}

1. Manning, JT, Scutt D, Wilson J, Lewis-Jones DI. The ratio of 2 nd to 4th digit length: a predictor of sperm numbers and concentrations of testosterone, luteinizing hormone and oestrogen. Hum Reprod 1998;13:3000-4. [CrossRef]

2. Hönekopp J, Watson S. Meta-analysis of digit ratio 2D:4D shows greater sex difference in the right hand. Am J Hum Biol 2010;22:619-30. [CrossRef]

3. Klimek M, Galbarczyk A, Nenko I, Jasienska G. Women with more feminine digit ratio(2D:4D) have higher reproductive success. Am J Phys Anthropol 2016;160:549-53. [CrossRef]

4. Herault Y, Fraudeau N, Zakany J, Duboule D. Ulnaless (Ul), a regulatory mutation inducing both loss-of-function and gain-offunction of posterior Hoxd genes. Development 1997;124:3493500

5. Mortlock DP, Innis JW. Mutation of HOXA13 in hand-footgenital syndrome. Nat Genet 1997;15:179-80. [CrossRef]

6. Choi IH, Kim KH, Jung H, Yoon SJ, Kim SW, Kim TB. Second to fourth digit ratio: a predictor of adult penile length. Asian J Androl 2011;13:710-4. [CrossRef]

7. Bolat D, Kocabas GU, Kose T, Degirmenci T, Aydin ME, Dincel C. The relationship between the second-to-fourth digit ratios and lifelong premature ejaculation: a prospective, comparative study. Andrology 2017;5:535-40. [CrossRef]

8. Muller DC, Giles GG, Bassett J, Morris HA, Manning JT, Hopper $\mathrm{JL}$, et al. Second to fourth digit ratio (2D:4D) and concentrations of circulating sex hormones in adulthood. Reprod Biol Endocrinol 2014;9:57. [CrossRef]

9. World Health Organization, Department of Reproductive Health and Research. WHO Laboratory Manual for the Examination and Processing of Human Semen, 5th ed. WHO, 2010.
10. Auger J, Eustache F. Second to fourth digit ratios, male genital development and reproductive health: a clinical study among fertile men and testis cancer patients. Int J Androl 2010;34:e4958. [CrossRef]

11. Oh JK, Kim KT, Yoon SJ, Kim SW, Kim TB. Second to fourth digit ratio: a predictor of adult testicular volume. Andrology 2014;2:862-7. [CrossRef]

12. Hönekopp J, Bartholdt L, Beier L, Liebert A. Second to fourth digit length ratio (2D:4D) and adult sex hormone levels: new data and a meta-analytic review. Psychoneuroendocrinology 2007;32:31321. [CrossRef]

13. Xu Y, Zheng Y. The digit ratio (2D:4D) in China: A meta-analysis. Am J Hum Biol 2015;27:304-9. [CrossRef]

14. Bang AK, Carlsen E, Holm M, Petersen JH, Skakkebæk NE, Jørgensen NJ. A study of finger lengths semen quality and sex hormones in 360 young men from the general Danish population. Hum Reprod 2005;20:3109-13. [CrossRef]

15. Lu H, Huo Z, Liu Y, Shi Z, Zhao J. Correlations between digit ratio and infertility in Chinese men. Early Hum Dev 2012;88:865-9. [CrossRef]

16. Firman RC, Simmons LW, Cummins JM, Matson PL. Are body fluctuating asymmetry and the ratio of 2 nd to 4 th digit length reliable predictors of semen quality? Hum Reprod 2003; 18:80812. [CrossRef]

17. Seo $\mathrm{H}$, Kim KY, Rho J. Is the index finger and ring finger ratio $2 \mathrm{D}: 4 \mathrm{D}$ reliable predictor of semen quality? Korean J Urol 2010;51:208-11. [CrossRef]

18. Akinsal EC, Demirtas A, Ekmekcioglu O. Comparison of the Ratio of the Lenght of the Second and Fourth Digits in Subgroups of Fertile and Infertile Cases. Urology J 2017;14:3081-4. 